\title{
Verification of the MIKE11-NAM Model for Simulating Streamflow
}

\author{
Fitsum T. Teshome ${ }^{1,2 *}$, Haimanote K. Bayabil², L. N. Thakural ${ }^{3}$, Fikadu G. Welidehanna² \\ ${ }^{1}$ Department of Plant Science, College of Agriculture and Natural Resources, Madda Walabu University, Bale-Robe, Ethiopia \\ ${ }^{2}$ Department of Agricultural and Biological Engineering, Tropical Research and Education Center, IFAS, University of Florida, \\ Homestead, FL, USA \\ ${ }^{3}$ Surface Water Hydrology Division, National Institute of Hydrology, Roorkee, India \\ Email: ${ }^{\star}$ fteshome@ufl.edu
}

How to cite this paper: Teshome, F.T., Bayabil, H.K., Thakural, L.N. and Welidehanna, F.G. (2020) Verification of the MIKE11-NAM Model for Simulating Streamflow. Journal of Environmental Protection, 11, 152-167.

https://doi.org/10.4236/jep.2020.112010

Received: January 23, 2020

Accepted: February 25, 2020

Published: February 28, 2020

Copyright $\odot 2020$ by author(s) and Scientific Research Publishing Inc. This work is licensed under the Creative Commons Attribution International License (CC BY 4.0).

http://creativecommons.org/licenses/by/4.0/

(c) (i) Open Access

\begin{abstract}
Modeling watershed hydrological processes are important for water resources planning, development, and management. In this study, the MIKE 11-NAM (Nedbor-Afstromings Model model) was evaluated for simulation of streamflow from the Bina basin located in the Madhya Pradesh State of India. The model was calibrated and validated on a daily basis using five years (1994-1998) observed hydrological data. In addition, a model sensitivity analysis was performed on nine MIKE 11-NAM parameters to identify sensitive model parameters. Statistical and graphical approaches were used to assess the performance of the model in simulating the streamflow of the basin. Results show that during daily model calibration, the model performed very well with a coefficient of determination $\left(\mathrm{R}^{2}\right)$ and the percentage of water balance error (WBL) values $0.87 \%$ and $-8.63 \%$, respectively. In addition, the model performed good during the validation period with $\mathrm{R}^{2}$ and WBL values of $0.68 \%$ and $-6.72 \%$, respectively. Model sensitivity analysis results showed that Overland flow runoff coefficient (CQOF), Time constant for routing overland flow $(\mathrm{CK} 1,2)$ and Maximum water content in root zone storage $\left(\mathrm{L}_{\max }\right)$ were found as the most influential and sensitive model parameters for simulating streamflow. Overall, the model's performance was satisfactory based on $\mathrm{R}^{2}$ and EI metrics.
\end{abstract}

\section{Keywords}

Lumped Conceptual Model, MIKE 11-NAM, Sensitivity Analysis, Rainfall-Runoff Modeling

\section{Introduction}

Water is a vital resource for sustainable socio-economic development. However, 
population growth and industrialization are driving an increasing demand for freshwater [1]. On the contrary, the water resource is depleting from time to time as a result of anthropogenic activities such as deforestation, environmental pollution, and rapid population growth [2]. The water crisis is becoming a global phenomenon [3]. The water crisis is severe in many parts of Madhya Pradesh, India, for example in Bina river basin in Bina municipality in Sagar district. According to the National Institute of Disaster Management [4], around 132 tehsils in 18 districts are declared drought-hit due to drastic fall in the water table and/or extreme dry rivers which have affected severe water shortages in more than half the state. To overcome or minimize the water crisis impact in this area, it is mandatory to develop a water resource management strategy by improved understanding of the hydrological behavior of the area. The rainfall-runoff modeling is an effective tool to examine the hydrological behavior [5].

The surface water modeling such as runoff is one of the most frequently applied studies in hydrology for predicting the peak river flow or the hydrograph generated by an observed or a hypothetical rainfall [6] [7]. NAM is an abbreviation for "Nedbor-Afstromings Model", a Danish: Denmark word with a translation ("precipitation runoff model") is a well-proven and broadly used hydrological tool that has been applied in several catchments worldwide, representing different hydrological regimes and climatic conditions. Previously, Rahman et al. [8] developed a flood forecasting system for large Jamuneswari River basin, Bangladesh using MIKE 11-NAM model. Ferdous [9] developed the hydrological model system for the lower Rideau River sub-watershed, Ontario, Canada using MIKE 11-NAM hydrological model. MIKE 11-NAM is a deterministic, lumped conceptual rainfall-runoff model which is a set of linked mathematical statements describing, in a simplified quantitative form, the characteristics of the land area of the hydrological cycle [10]. MIKE 11-NAM model simulates the rainfall-runoff process in rural catchments and has 9 parameters: Maximum water content in surface storage $\left(\mathrm{U}_{\max }\right)$, Maximum water content in root zone storage $\left(\mathrm{L}_{\max }\right)$, Overland flow runoff coefficient (CQOF), Time constant for routing interflow $\left(\mathrm{CK}_{\mathrm{IF}}\right)$, Time constant for routing overland flow $(\mathrm{CK} 1,2)$, Root zone threshold value for overland flow (TOF), Root zone threshold value for inflow (TIF), Root zone threshold value for GW recharge (TG) and Time constant for routing base flow $\left(\mathrm{CK}_{\mathrm{BF}}\right.$ ) (snow storage was not considered in this study). Thus, some of the parameters can be evaluated from physical catchment data, but the final parameter estimation must be performed by calibration applying concurrent input and output time series [11]. MIKE 11-NAM model operates by continuously accounting for the water content in four different and mutually interrelated storages whereby each storage represents different physical elements of the catchment [12]. The input data to the model are precipitation, potential evapotranspiration, and temperature (only if the snow routine is used). On this basis, it produces, as main results, runoff and groundwater level values as well as information about other elements of the land area of the hydrological cycle, such 
as the temporal variation of the soil moisture content. The main objective of this study was to evaluate the performance of the MIKE 11-NAM model to simulate runoff in a catchment area.

\section{Materials and Methods}

\subsection{Description of Study Area}

This study was conducted in Bina river (an important tributary of the Betwa River) basin, in Bina province, Madhya Pradesh, India (Figure 1). Bina River originates from Begumganj block of Raisen district and enters Sagar district at Rahatgarh block and traverses through Khurai and Bina tehsil before the confluence with river Betwa near Basoda town in Vidisha district [13]. Bina basin falls between $23^{\circ} 3^{\prime} \mathrm{N}$ to $24^{\circ} 3^{\prime} \mathrm{N}$ latitudes and $78^{\circ} 1^{\prime} \mathrm{E}$ to $78^{\circ} 6^{\prime} \mathrm{E}$ longitudes having a total geographical area of $2822 \mathrm{sq} \cdot \mathrm{km}$.

\subsection{MIKE 11-NAM Model}

Several hydrological deterministic models have been developed to simulate the rainfall-runoff process for river watersheds, however, most have complicated structures and need various observed data. Streamflow simulation using the SWAT model was performed in the same river basin and the abovementioned

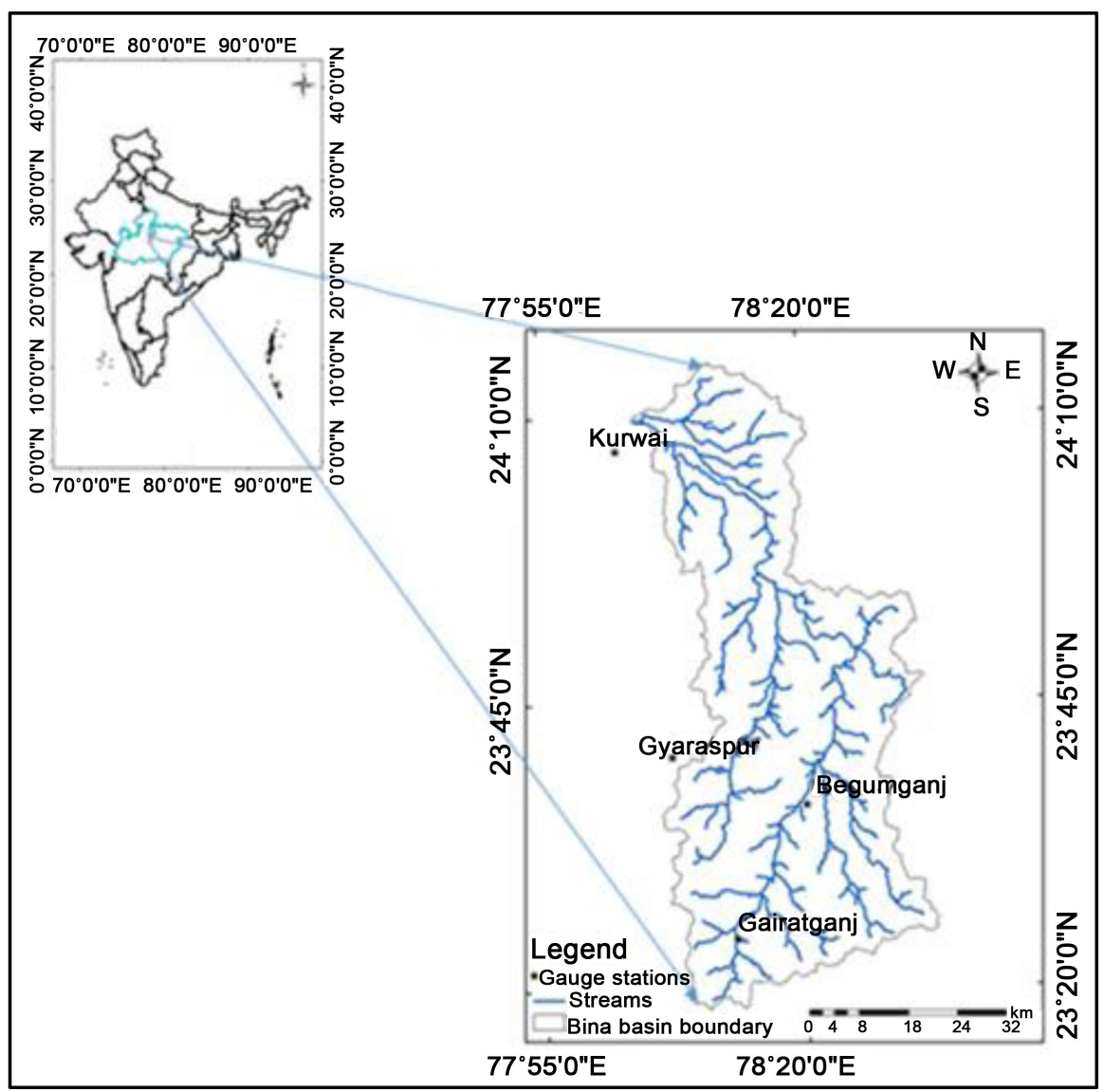

Figure 1. Location map of the study area. 
drawbacks were experienced. The MIKE11-NAM rainfall-runoff model has been broadly employed in many Asian countries not only for the reason that it is fewer data requirements but also because it is decent performance and straightforward structures [14]. However, this hydrological model needs extensive time and effort to calibrate the model parameters through a manual calibration method. A lumped conceptual model of the MIKE 11-NAM Model treats each sub-catchment area as a single homogenous unit [7].

The model structure is shown in Figure 2. It is an imitation of the land phase of the hydrological cycle. The various components of the rainfall-runoff process represent the average values for the entire sub-catchment by continuously accounting for water contents in 4 different but mutually interrelated forms of storage, namely: snow, overland flow, interflow, and baseflow, as shown in Figure 2, is also based on the linear reservoir.

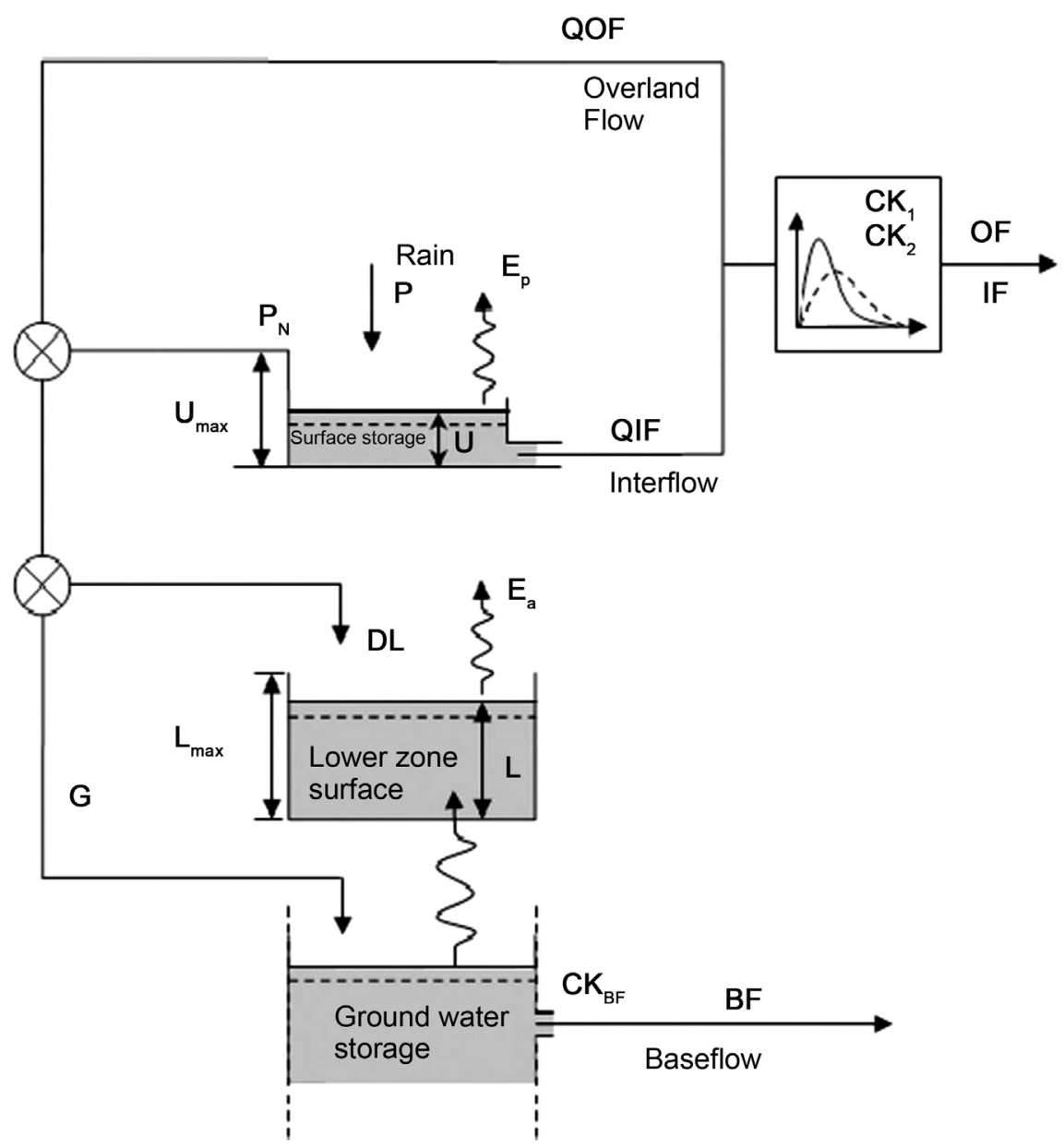

Figure 2. Structure of the NAM model (Source: [15]) (P is precipitation, $\mathrm{E}_{\mathrm{p}}$ is potential evapotranspiration, $\mathrm{E}_{\mathrm{a}}$ is actual evapotranspiration, $\mathrm{U}_{\max }$ is maximum water content in surface storage, $\mathrm{L}_{\max }$ is maximum water content in root zone storage, $\mathrm{P}_{\mathrm{N}}$ is excess water, $\mathrm{L}$ is moisture content in root zone storage, $\mathrm{U}$ is moisture content in surface storage, $\mathrm{CK}_{1}$ and $\mathrm{CK}_{2}$ are time constant for routing overland flow, $\mathrm{G}$ is infiltrating water, QIF is interflow, QOF is overland flow, $\mathrm{CK}_{\mathrm{BF}}$ is Time constant for routing base flow and BF is baseflow). 


\subsection{Data Requirements}

The basic input requirements for the MIKE11-NAM model consist of model parameters, initial conditions, meteorological and hydrological data.

\subsubsection{Model Parameters}

The model parameters were determined for calibration and Validation: MIKE11-NAM works with several parameters divided into four groups: Surface and Root zone, Groundwater, Snowmelt, Irrigation. For this study we have not used irrigation parameters due to the nonexistence of intensive irrigation practice during the monsoon season, also the snowmelt parameters have been omitted because the temperature in this province never been below freezing point. Therefore, only 9 parameters were calibrated and validated. Those parameters are $\mathrm{U}_{\max }, \mathrm{L}_{\max }$, CQOF, $\mathrm{CK}_{\mathrm{IF}}, \mathrm{CK} 1,2, \mathrm{TOF}, \mathrm{TIF}$, TG and $\mathrm{CK}_{\mathrm{BF}}$, snow storage was not considered in this study.

\subsubsection{Initial Conditions}

Initial conditions represent the state of the basin at the beginning of the storm event. The initial conditions required by the MIKE11-NAM model consist of the initial water contents in the surface and root zone storages, together with initial values of overland flow, interflow, and baseflow. When a simulation begins at the end of a dry period, it is often enough to set all initial values to zero, except the water content in the root zone and the baseflow. The water content in the root zone should be about $10 \%-30 \%$ of the capacity and the baseflow should be given a value close to the observed discharge [16].

\subsubsection{Meteorological and Hydrological Data}

Precipitation: The time resolution of the precipitation input depends on the objective of the study and on the time scale of the catchment response. In this study daily precipitation $(\mathrm{mm})$ data of four rain gauge stations of Bina basin i.e. Begumganj, Gairatganj, Gyaraspur, and Kurwai for a period of 1994-1996 and 1997-1998 were used for calibration and validation purpose respectively, which were collected from Madhya Pradesh State Data Center (MPSDC), Bhopal and treated as step accumulated totals.

The MIKE11-NAM model simulates the rainfall-runoff process in a lumped fashion, so provision is given for combining meteorological data from different stations within a single catchment or sub-catchment into a single time series of weighted averages [17]. The resulting time series will represent the mean area values of rainfall for a catchment. In this, a study Thiessen polygon method was used to estimate a weighted average of precipitation and this Thiessen polygon was prepared by using Arc GIS 10.5 software. In the Thiessen polygon method, the precipitation recorded at each station was given a weight based on an area closest to the station. If $P_{1}, P_{2}, P_{3}, \cdots, P_{n}$ is the precipitation magnitude recorded by the stations $1,2,3, \cdots, n$ respectively, and $A_{1}, A_{2}, A_{3}, \cdots, A_{n}$ are the respective areas of the Thiessen polygons and average precipitation over the catchment $\bar{P}$ 
is given by

$$
\bar{P}=\frac{\sum_{i=1}^{n} \bar{P}_{i} * A_{i}}{A} \text { thus, in general, for } n \text { stations }
$$

The ratio $A_{i} / A$ is called the weighted factor for each station.

The Thiessen-polygon method of calculating the average precipitation over an area is superior to the arithmetic average method as some weighted is given to the various stations on a rational basis. Further, the gauge stations outside the catchment area also used effectively [18].

Potential Evapotranspiration: In the present study daily potential evapotranspiration (mm) data for a period of 1994-1996 and 1997-1998 were used for calibration and validation purposes respectively and potential evapotranspiration treated as step accumulated totals. Daily maximum temperature, minimum temperature and radiation of Sagar station from Madhya Pradesh State Data Center (MPSDC, Bhopal) for the period of 1994 to 1998 were used for estimation of potential evapotranspiration [19], as shown below:

$$
P E T=m R\left(T_{\text {avg }}+17.8\right)\left(T_{\max }-T_{\min }\right)^{0.5}
$$

where $P E T=$ Potential Evapotranspiration $(\mathrm{mm} /$ day)

$$
\begin{aligned}
& m=\text { Constant }=0.0009384 \\
& R=\text { Radiation }\left(\mathrm{MJ} / \mathrm{m}^{2}\right) \\
& T_{\max }=\text { Maximum Temperature }\left({ }^{\circ} \mathrm{C}\right) \\
& T_{\min }=\text { Minimum Temperature }\left({ }^{\circ} \mathrm{C}\right) \\
& \qquad T_{\text {avg }}=\frac{T_{\min }+T_{\max }}{2}\left({ }^{\circ} \mathrm{C}\right)
\end{aligned}
$$

Discharge: Observed discharge data at the catchment outlet are required for comparison with the simulated runoff for model calibration and validation. In the present study, daily discharge data of Bina province in cubic meter per second $\left(\mathrm{m}^{3} / \mathrm{s}\right)$ for a period ranging from 1994-1996 and 1997-1998 were used for calibration and validation purposes respectively and the discharge treated as Instantaneous.

\subsection{Model Setup}

The NAM model simulates the rainfall-runoff process in a lumped fashion so provision was given in combined meteorological data from four gage stations of Bina basin specifically Begumganj, Gairatganj, Gyaraspur and Kurwai into a single time series of weighted averages, in such a manner which represent the entire basin. Bina basin Thiessen polygon map is shown in Figure 3. The areal precipitation was computed by multiplying the precipitation at each station and their calculated percentage weight. The percentage weights were used for the mean areal rainfall input, in the MIKE11-NAM model. The percentage weights input according to their contribution rank into the MIKE11-NAM model are shown in Table 1. 


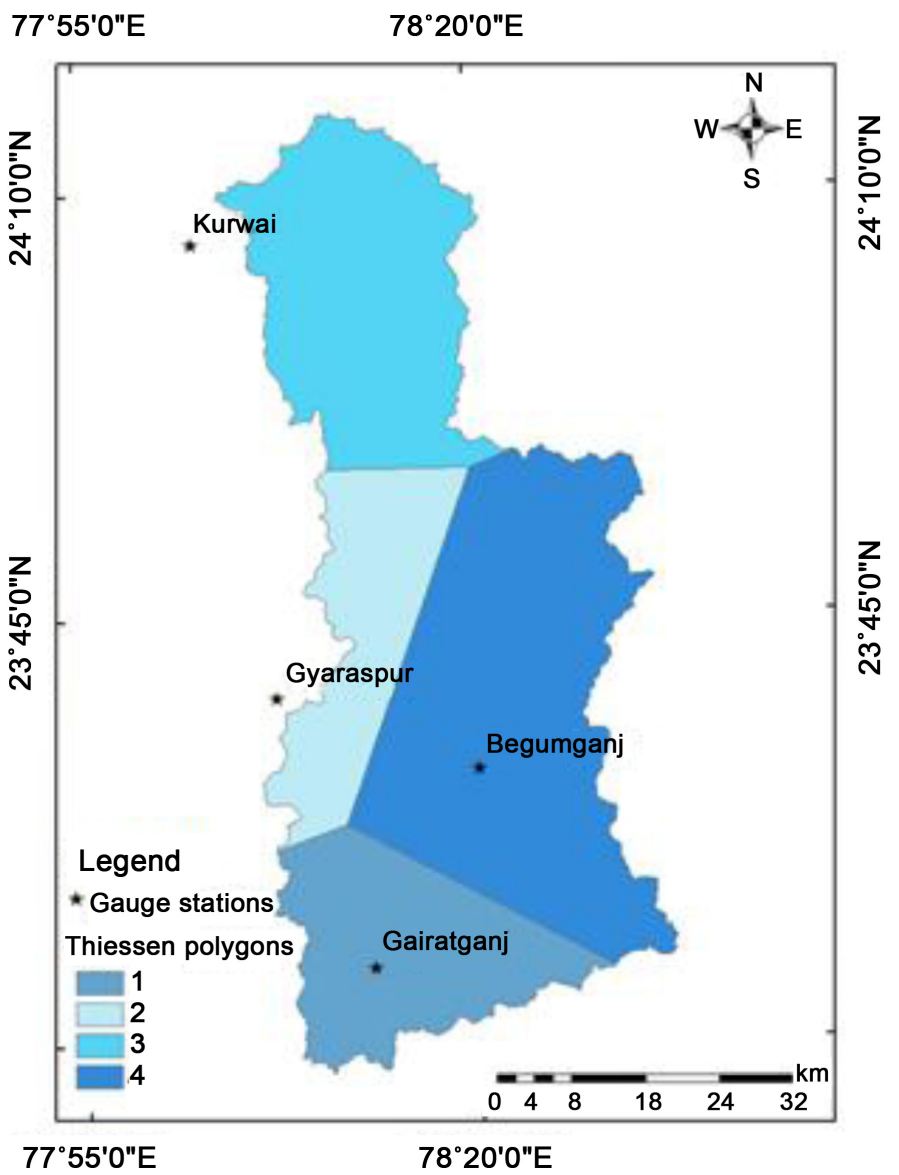

Figure 3. Thiessen polygon map of rain gauge stations in Bina river basin (Polygon 1, 2, 3 and 4 represent Thiessen polygon results for Gairatganj, Gyaraspur, Kurwai, and Begumganj meteorological stations respectively).

Table 1. Areal percentage weights of rain gauge stations found in Bina river basin.

\begin{tabular}{cccc}
\hline Sr.No & Rain gauge Station & Area $\left(\mathbf{k m}^{2}\right)$ & Weights $(\%)$ \\
\hline 1 & Begumganj & 1153.56 & 41 \\
2 & Kurwai & 734.01 & 26 \\
3 & Gairatganj & 521.23 & 18 \\
4 & Gyaraspur & 413.64 & 15 \\
\hline
\end{tabular}

The first step in MIKE 11-NAM modeling is to examine the relationship between precipitation and streamflow, which is crucial for accurate modeling of streamflow. A commonly adopted method is to fit a linear regression line between Runoff and Precipitation and to accept the result if the correlation coefficient is nearer to 1 . In this study, the correlation was tested by computing the coefficient of determination $\left(\mathrm{R}^{2}\right)$ between precipitation and discharge data and it was found as 0.87 as shown in Figure 4. And this value indicated that the precipitation data has a strong positive correlation with discharge data, which was reliable to be used for rainfall-runoff modeling. 


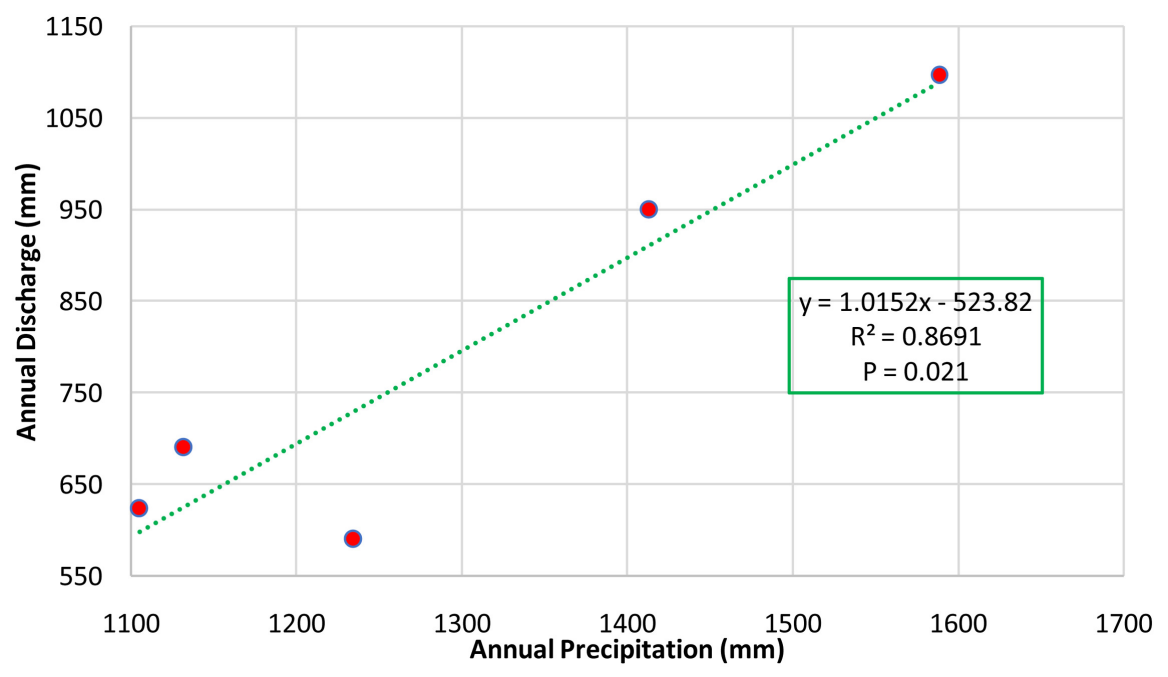

Figure 4. Scatter plot of mean annual precipitation and discharge data of Bina river basin for the period of 1994-1998 (Calibration and Validation periods).

Estimation of the runoff coefficient before the calibration process was another important step for gaining a hint about the Overland flow coefficient (CQOF) in the calibration of the model. Runoff coefficient is a part of the precipitation, which is converted into a runoff, was also calculated by dividing annual precipitation by observed annual runoff and shown in Table 2 . The values of the runoff coefficient varied from 0.48 to 0.69 . The average annual potential evapotranspiration $\left(\mathrm{ET}_{\mathrm{O}}\right)$ was estimated at $931.366 \mathrm{~mm}$.

\subsection{Calibration, and Validation}

The parameters of MIKE11-NAM could not be found direct from measurable quantities of basin characteristics and therefore, model calibration is necessary. Calibration is a process of modifying model parameters to reduce the error between the simulated and observed streamflow. In the MIKE 11-NAM model, a manual way of model calibration is practiced.

In manual calibration, a trial-and-error parameter adjustment is performed, based on a visual judgment by comparing the measured and the predicted discharge. Auto-calibration, the default model parameters were kept the same and the model was run in auto-calibration mode [20]. After several manual calibrations have been made the calibration was done again with very small changes. To check the quality of the results, the calibration was checked for the coefficient of determination $\left(\mathrm{R}^{2}\right)$, water balance error (\%WBL) values and graphically analyzed for the degree of agreement between simulated and observed runoff.

Model validation means evaluating the capability of the calibrated model. According to Refsgaard and Knudsenn [21], a model is said to be validated if its accuracy and predictive capacity in the verification period have been proven to lie within acceptable limits. The verification is implemented by using the new set of observed data and the parameters that have been calibrated in the previous step. 
Table 2. Runoff coefficient results of Bina river basin for the period of 1994-1998 (Calibration and Validation periods).

\begin{tabular}{ccccc}
\hline Year & $\begin{array}{c}\text { Evapotranspiration } \\
(\mathrm{mm})\end{array}$ & $\begin{array}{c}\text { Annual Discharge } \\
(\mathrm{mm})\end{array}$ & $\begin{array}{c}\text { Annual Rainfall } \\
(\mathrm{mm})\end{array}$ & $\begin{array}{c}\text { Runoff } \\
\text { Coefficient }\end{array}$ \\
\hline 1994 & 939.46 & 950.3 & 1413.1 & 0.67 \\
1995 & 970.18 & 623.9 & 1105.1 & 0.56 \\
1996 & 960.93 & 690.4 & 1131.9 & 0.61 \\
1997 & 854.63 & 1097.1 & 1588.6 & 0.69 \\
1998 & 931.63 & 590.2 & 1234.2 & 0.48 \\
\hline
\end{tabular}

\subsection{Model Performance}

The performance of the model can be examined based on the coefficient of determination $\left(\mathrm{R}^{2}\right)$, the use of the coefficient of determination is to test the goodness of fit of the model and to assess how well a model explains and predicts future outcomes. Efficiency Index (EI) was another hydrological model assessor as described by Nash and Sutcliffe [22] which had been widely used to detect the model error for the long-term simulation. The EI was developed to evaluate the percentage of accuracy of the simulated values with respect to their observed values. EI values equal to 1 signifies the accurate performance of the model.

EI, $\mathrm{R}^{2}$, and \%WBL have defined as:

$$
\begin{gathered}
\mathrm{EI}=\frac{\sum_{i=1}^{n}\left(O_{i}-\bar{O}\right)^{2}-\sum_{i=1}^{n}\left(O_{i}-P_{i}\right)^{2}}{\sum_{i=1}^{n}\left(O_{i}-\bar{O}\right)^{2}} \\
\mathrm{R}^{2}=1-\frac{\sum_{i=1}^{n}\left(O_{i}-P_{i}\right)^{2}}{\sum_{i=1}^{n}\left(O_{i}-\bar{O}\right)^{2}} \\
\% \mathrm{WBL}=\frac{\sum_{i=1}^{n} P_{i}-\sum_{i=1}^{n} O_{i}}{\sum_{i=1}^{n} O_{i}} * 100
\end{gathered}
$$

In these equations, $O_{i}$ and $P_{i}$ are $i^{\text {th }}$ observed and simulated values, respectively, $\bar{O}$ is mean value for observed and $n$ is the number of samples.

\subsection{Sensitivity Analysis}

In MIKE 11-NAM model, the most sensitive model parameters are identified by changing the value of one of the model parameters and keeping the value of the remaining parameters constant [23]. The model parameters were picked one after another and their values obtained during the calibration increased and decreased by $10 \%$ and $20 \%$ to both sides. The analysis results were plotted against the EI and $\mathrm{R}^{2}$ of the model and the most sensitive model parameters were identified. The sensitivity of the parameters depends on how it affects the value of EI and $\mathrm{R}^{2}$ of the model.

\section{Results and Discussion}

\subsection{Model Calibration and Validation}

Once the model was set up with the input information, the calibration has been 
carried out from 1994 to 1996 . These optimum values are considered as the representative coefficient to determine the runoff within the catchment area. Table 3 illustrates the final values of parameters that have been adjusted in the calibration process. Figure 5 shows the comparison of simulated and observed discharge data during the past three year's runoff (1994 to 1996) in rate $\left(\mathrm{m}^{3} / \mathrm{s}\right)$. The comparison shows a good match of simulated data with the observed data and a good overall agreement of the shape of the hydrograph with respect to timing, rate, and volume. Similar results were reported by several authors i.e. Hafezparast et al. [24] simulated Sarsoo river basin streamflow using the MIKE 11-NAM model. They found that a significantly a good agreement between the

Table 3. Optimal, lower bound and upper bound values of best parameters.

\begin{tabular}{|c|c|c|c|c|c|c|}
\hline No & Parameters & Description of parameters & Unit & $\begin{array}{l}\text { Optimal } \\
\text { value }\end{array}$ & Lower-Bound & Upper-Bound \\
\hline 1 & $\mathrm{U}_{\max }$ & $\begin{array}{l}\text { Maximum water content } \\
\text { in surface storage }\end{array}$ & $\mathrm{mm}$ & 12.90 & 10 & 20 \\
\hline 2 & $\mathrm{~L}_{\max }$ & $\begin{array}{l}\text { Maximum water content } \\
\text { in root zone storage }\end{array}$ & $\mathrm{mm}$ & 156 & 100 & 300 \\
\hline 3 & CQOF & $\begin{array}{l}\text { Overland flow runoff } \\
\text { coefficient }\end{array}$ & & 0.72 & 0.1 & 1 \\
\hline 4 & CKIF & $\begin{array}{l}\text { Time constant for routing } \\
\text { interflow }\end{array}$ & hrs & 496.60 & 200 & 1000 \\
\hline 5 & CK1,2 & $\begin{array}{l}\text { Time constant for routing } \\
\text { overland flow }\end{array}$ & hrs & 15.70 & 10 & 50 \\
\hline 6 & TOF & $\begin{array}{l}\text { Root zone threshold value for } \\
\text { overland flow }\end{array}$ & & 0.10 & 0 & 0.99 \\
\hline 7 & TIF & $\begin{array}{l}\text { Root zone threshold value for } \\
\text { inflow }\end{array}$ & & 0.16 & 0 & 0.99 \\
\hline 8 & TG & $\begin{array}{l}\text { Root zone threshold value } \\
\text { for GW recharge }\end{array}$ & & 0.34 & 0 & 0.99 \\
\hline 9 & CKBF & $\begin{array}{l}\text { Time constant for routing } \\
\text { base flow }\end{array}$ & hrs & 3250 & 1000 & 4000 \\
\hline
\end{tabular}

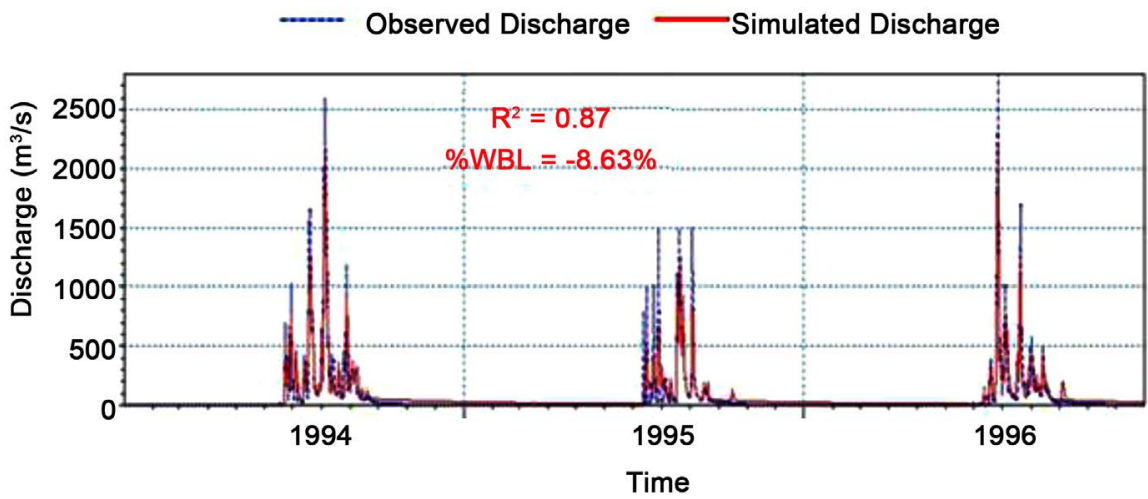

Figure 5. Observed and simulated hydrographs of monthly streamflow at the Bina river basin for the period of 1994-1996 (Calibration periods). 
observed and simulated flow values. A study by Amir et al. [20] at Fitzroy basin, Australia using the MIKE 11-NAM model found that there is a good hydrographs agreement between observed and simulated discharge which shows the ability of the model to simulate the streamflow the basin. Odiyo et al. [25] simulated Latonyanda River Quaternary catchment (LRQ) streamflow using MIKE 11 NAM model and, found that the observed and the simulated streamflow for LRQ catchment correlated well except for under-prediction of peak events and a few low flows.

The simulated values of different components of the hydrological cycle, such as Potential evapotranspiration, Actual evapotranspiration, Groundwater recharge, Runoff, Overland flow, Interflow, and Baseflow simulated during model calibration are shown in Table 4 in the form of water balance $(\mathrm{mm})$. The coefficient of determination $\left(\mathrm{R}^{2}\right)$ and water balance error (\%WBL) for the model calibration was obtained $0.87 \%$ and $-8.63 \%$ respectively as presented in Figure 5, which indicated that the model calibrated efficiently and could simulate the runoff of the catchment. The comparison of observed and simulated mean monthly discharge is shown in Figure 6. It was observed that good agreement between the averages simulated and observed basin discharge.

The 1997 and 1998 time series had been used for checking the validity of the model. During validation, the set of model parameters acquired during the

Table 4. Water balance distributions for calibration periods (1994-1996).

\begin{tabular}{cccccccccccc}
\hline Period & Q-Obs & Q-Sim & \%diff & \multicolumn{2}{c}{ Rainfall } & PotEvap & ActEvap & Recharge & OF & IF & BF \\
\hline 1994 & 950.3 & 971.4 & 0 & 1413.1 & 937.5 & 372.1 & 319.4 & 707.5 & 45.1 & 9.1 \\
1995 & 623.9 & 716.5 & -0.1 & 1105.1 & 970.2 & 394.9 & 215.2 & 449.1 & 34.5 & 9.7 \\
1996 & 690.4 & 772.4 & -0.1 & 1131.9 & 961 & 352.3 & 237 & 501.8 & 38.8 & 9.7 \\
Overall & 2264.6 & 2460.3 & -0.1 & 3650.1 & 2868.7 & 1119.3 & 771.7 & 1658.4 & 118.4 & 28.5 \\
\hline
\end{tabular}

Q-Obs = Observed Discharge, Q-sim $=$ Simulated Discharge, \%diff $=$ Difference between Observed and Simulated Discharge PotEvap $=$ Potential Evapotranspiration, ActEvap $=$ Actual Evapotranspiration, $\mathrm{OF}=$ Overland Flow, $\mathrm{IF}=$ Inter Flow and $\mathrm{BF}=$ Base Flow.

- Observed Discharge - Simulated Discharge

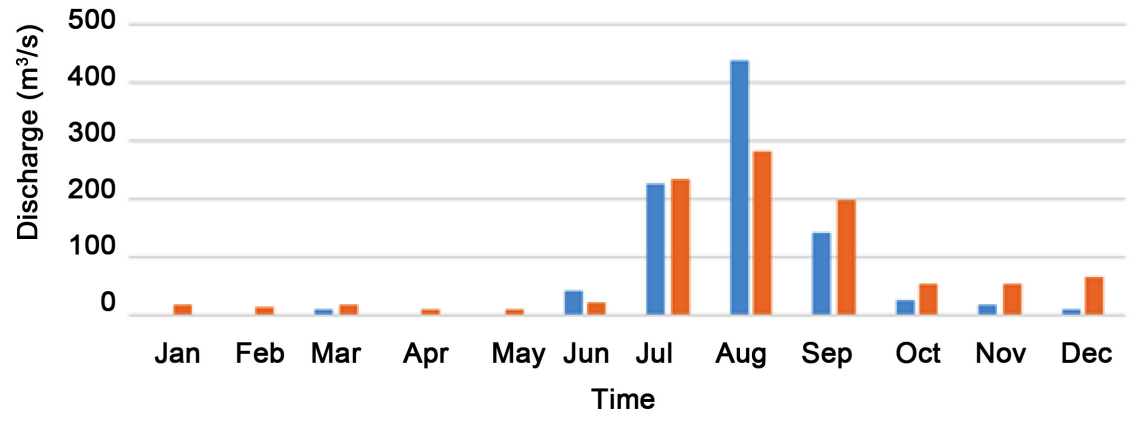

Figure 6. Mean monthly histogram of observed and simulated streamflow of the Bina river basin for the period of 1994 to 1996 (Calibration periods). 
calibration was served to simulate the runoff. Figure 7 and Table 5 represents the results of model validation. The coefficient of determination $\left(\mathrm{R}^{2}\right)$ and water balance error (\%WBL) for the model validation was observed $0.68 \%$ and $-6.72 \%$ respectively as shown in Figure 7, which indicated the capability of the model to estimate runoff for periods outside that used to calibrate the model. A study conducted by Tiwari et al. [26] on the Shipra river basin using the MIKE 11-NAM model found that the model is suitable for simulating the streamflow of the basin for the extended time period.

The simulated values of different components of the hydrological cycle, such as Potential evapotranspiration, Actual evapotranspiration, Groundwater recharge, Runoff, Overland flow, Interflow, and Baseflow simulated during model validation are shown in Table 5 in the form of water balance $(\mathrm{mm})$. The comparison of observed and simulated mean monthly runoff volume is shown in Figure 8, it was detected that good agreement between the averages simulated and observed basin runoff volume for validation period, this shows the model could calibrate runoff outside the calibration periods.

\subsection{Model Performance}

The reliability of the MIKE11-NAM was evaluated based on the coefficient of determination $\left(\mathrm{R}^{2}\right)$. It is expressed as a value between zero and one and it is obtained 0.87 . The reliability of the MIKE11-NAM was also evaluated based on the

Table 5. Water balance distributions for validation periods (1997-1998).

\begin{tabular}{ccccccccccc}
\hline Period & Q-Obs & Q-Sim & \%diff & Rainfall & PotEvap & ActEvap & Recharge & OF & IF & BF \\
\hline 1997 & 1097.1 & 971.6 & 0.1 & 1588.6 & 852.5 & 396.1 & 345.6 & 732.5 & 58.3 & 7.5 \\
1998 & 590.2 & 829.5 & -0.3 & 1234.2 & 931.7 & 515.4 & 243.2 & 492.2 & 45.1 & 12.2 \\
Overall & 1687.3 & 1801.1 & -0.1 & 2822.8 & 1784.2 & 911.4 & 588.7 & 1224.7 & 103.4 & 19.7 \\
\hline
\end{tabular}

Q-Obs = Observed Discharge, $\mathrm{Q}$-sim $=$ Simulated Discharge, \%diff $=$ Difference between Observed and Simulated Discharge PotEvap = Potential Evapotranspiration, ActEvap = Actual Evapotranspiration, OF = Overland Flow, IF = Inter Flow and BF = Base Flow.

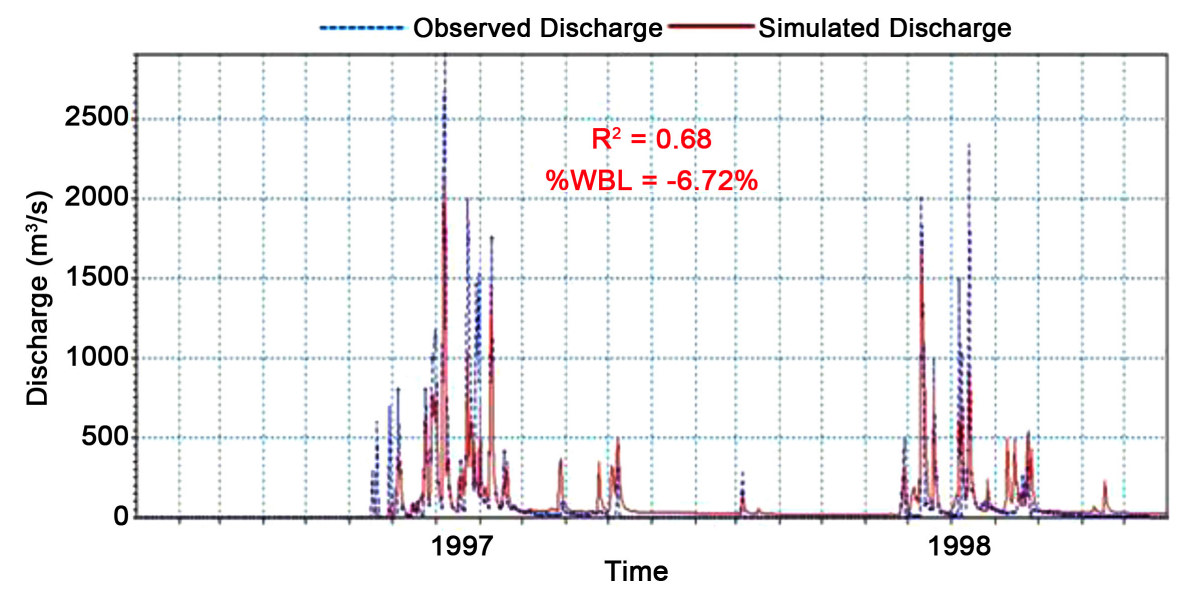

Figure 7. Observed and simulated hydrographs of monthly streamflow at the Bina river basin for the period of 1997-1998 (Validation periods). 


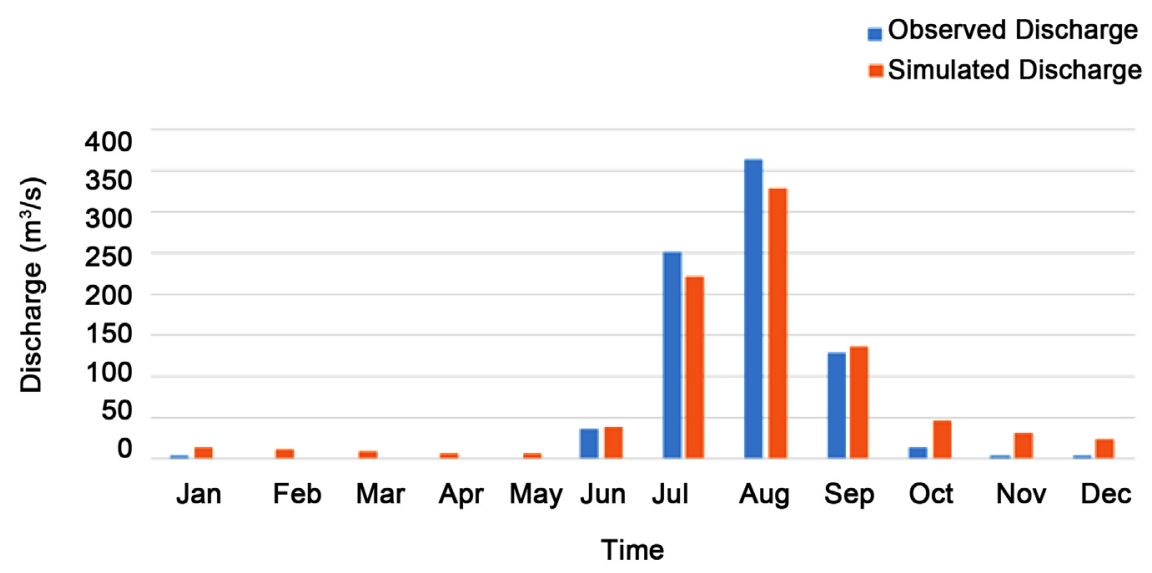

Figure 8. Mean monthly histogram of observed and simulated streamflow of the Bina river basin for the period of 1997 to 1998 (Validation periods).

efficiency index (EI) as described by Nash and Sutcliffe (1996). The EI was developed to evaluate the percentage of accuracy or goodness of the simulated values with respect to their observed values. The efficiency index (EI) equal to 1 indicates the best (perfect) performance of the model. The EI obtained during this study was 0.87 . Both evaluation criteria have shown a good result, which means the model is good enough to simulate the runoff of the catchment. Refsgaard and Knudsen [21] showed that the hydrological model is considered as valid when $\mathrm{R}^{2}>0.80$ and $\% \mathrm{WBL}<10 \%$.

\subsection{Sensitivity Analysis}

The sensitivity analysis of the MIKE11-NAM model was carried out by running the model by selecting model parameters one by one as a variable and keeping other parameters constant to identify the most sensitive model parameters. For each simulated runoff time series, EI and $\mathrm{R}^{2}$ were calculated using Equations (3) and (4) respectively. The output results were analyzed by plotting EI and $\mathrm{R}^{2}$ against the respective model parameters. The model parameters CQOF, CK1,2 and $\mathrm{L}_{\max }$ were found as the most influencing and sensitive parameters as shown in Figure 9. Whereas, the remaining parameters were found non-sensitive. Therefore, the significant parameters are CQOF, CK1,2 and $\mathrm{L}_{\max }$ because they result in the high differences in EI and $\mathrm{R}^{2}$ magnitude. Our results were supported by various authors viz. Rainfall-Runoff modeling conducted by Yadav et al. [27] on the Sher river basin using MIKE-NAM 11 model reported that the model parameters CQOF, CK12 were the most sensitive ones. Shimelis [28] found that $\mathrm{U}_{\max }, \mathrm{L}_{\max }$, CQOF, and CK1,2 were the most sensitive MIKE11-NAM model parameters for predicting Upper Guder Catchment streamflow. In this study sensitivity analysis has played a significant role in the improvement in calibration on which parameters must be focused.

\section{Conclusion}

Watershed and basin scales modeling of hydrological processes is important for 

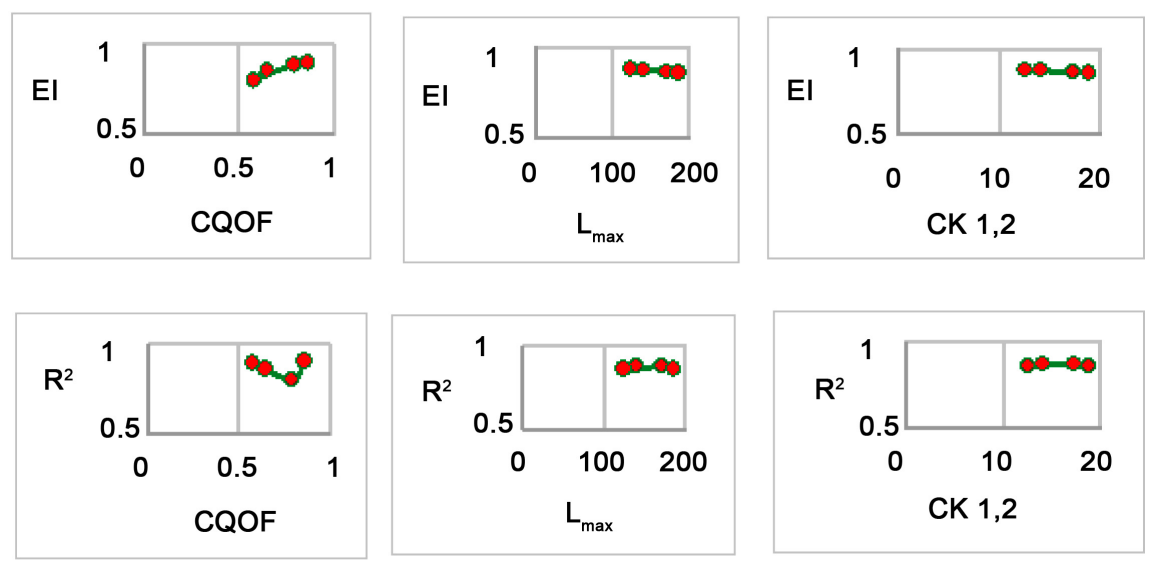

Figure 9. Scatter plot of sensitive model parameters and $\mathrm{R}^{2}$ and EI (CQOF is Overland flow runoff coefficient, CK1,2 is Time constant for routing overland flow and $\left(\mathrm{L}_{\max }\right.$ is Maximum water content in root zone storage, $\mathrm{R}^{2}$ is coefficient of determination and EI is efficiency index).

different purposes including water resources planning, development, and management. In this study, the performance of the MIKE 11-NAM model was evaluated for simulating streamflow of the Bina basin. Overall, the model performed satisfactorily in simulating monthly streamflow during both the calibration and validation periods. Results showed that the model had EI, R ${ }^{2}$, and \%WBL of $0.87,0.87 \%$ and $-8.63 \%$, respectively during the calibration period. The capability of the model was revealed by a good match of simulated data with the observed data and a good overall agreement of the shape of the hydrograph with respect to timing, rate, and volume. It should be also noted that the model's performance could potentially be further improved using more rainfall stations that effectively capture spatial rainfall distributions in the Bina river basin. However, given the simplicity and limited data requirements of the MIKE 11-NAM model makes it a useful tool to simulate streamflow especially in areas with limited data availability.

\section{Acknowledgements}

We thank the National Institute of Hydrology (NIH), Roorkee for providing the facilities to carry out this work. We also thank the staff of NIH for their encouragement and support.

\section{Conflicts of Interest}

The authors declare no conflicts of interest regarding the publication of this paper.

\section{References}

[1] United Nations Department of Economic and Social Affairs International Decade for Action "Water for Life" 2005-2015. Focus Areas: Water and Sustainable Development. 
https://www.un.org/waterforlifedecade/water and sustainable development.shtml

[2] Liyanage, C. and Yamada, K. (2017) Impact of Population Growth on the Water Quality of Natural Water Bodies. Sustainability, 9, 1405.

https://doi.org/10.3390/su9081405

[3] Guppy, L. and Anderson, K. Global Water Crisis: The Facts. https://inweh.unu.edu/wp-content/uploads/2017/11/Global-Water-Crisis-The-Facts .pdf

[4] National Institute of Disaster Management Annual Report 2017-18. https://nidm.gov.in/PDF/pubs/areport 17.pdf

[5] Moradkhani, H. and Sorooshian, S. (2008) General Review of Rainfall-Runoff Modeling: Model Calibration, Data Assimilation, and Uncertainty Analysis. In: Sorooshian, S., Hsu, K.-L., Coppola, E., Tomassetti, B., Verdecchia, M. and Visconti, G., Eds., Hydrological Modelling and the Water Cycle: Coupling the Atmospheric and Hydrological Models, Water Science and Technology Library, Springer, Berlin, Heidelberg, 1-24. https://doi.org/10.1007/978-3-540-77843-1 1

[6] Montanari, A. Rainfall-Runoff Modeling. Alberto Montanari. https://distart119.ing.unibo.it/albertonew/?q=node/58

[7] Sitterson, J., Knightes, C., Parmar, R., Wolfe, K., Muche, M. and Avant, B. (2017) An Overview of Rainfall-Runoff Model Types. 30.

[8] Rahman, M.M., Arya, D.S. and Goel, N.K. Development of Jamuneswari Flood Forecasting System-A Case Study in Bangladesh. Dr. Md. Mizanur Rahman and N. Goel, Academia.edu.

https://www.academia.edu/1177656/Development of Jamuneswari Flood Forecast ing System A Case Study in Bangladesh

[9] Ferdous, A. (2010) Numerical Modeling of the Rideau Valley Watershed. Natural Hazards, 55, 63-84. https://link.springer.com/article/10.1007/s11069-010-9588-4

[10] Agrawal, N. and Desmukh, T.S. (2016) Rainfall Runoff Modeling Using MIKE 11 Nam-A Review. International Journal of Innovative Science, Engineering \& Technology, 3, 9.

[11] DHI Mike_11_ref.pdf. https://manuals.mikepoweredbydhi.help/2017/Water Resources/Mike 11 ref.pdf

[12] Madsen, H. (2000) Automatic Calibration of a Conceptual Rainfall-Runoff Model Using Multiple Objectives. Journal of Hydrology, 235, 276-288. https://www.sciencedirect.com/science/article/pii/S0022169400002791 https://doi.org/10.1016/S0022-1694(00)00279-1

[13] Nayak, T.R., Gupta, S.K. and Galkate, R. (2015) GIS Based Mapping of Groundwater Fluctuations in Bina Basin. Aquatic Procedia, 4, 1469-1476. https://doi.org/10.1016/j.aqpro.2015.02.190

[14] Ngoc, T.A., Harada, M., Hiramatsu, K. and Harada, M. (2011) Parameter Identification for Two Conceptual Hydrological Models of Upper Dau Tieng River Watershed in Vietnam. Journal of Faculty of Agriculture Kyushu University, 56, 335-341.

[15] Willmott, C.J. (1981) On the Validation of Models. Physical Geography, 2, 184-194. https://doi.org/10.1080/02723646.1981.10642213

[16] DHI MIKE11_UserManual.pdf. https://manuals.mikepoweredbydhi.help/2017/Water Resources/MIKE11 UserMa nual.pdf

[17] DHI MIKE_1D_reference.pdf. 
https://manuals.mikepoweredbydhi.help/2017/Water Resources/MIKE 1D referen ce.pdf

[18] Shaw, E.M. and Lynn, P.P. (1972) Areal Rainfall Evaluation Using Two Surface Fitting Techniques. Hydrological Sciences Bulletin, 17, 419-433.

https://doi.org/10.1080/02626667209493855

[19] Hargreaves, G.H. (1989) Accuracy of Estimated Reference Crop Evapotranspiration. Journal of Irrigation and Drainage Engineering, 115.

https://ascelibrary.org/doi/10.1061/\%28ASCE\%290733-9437\%281989\%29115\%3A6 \%281000\%29 https://doi.org/10.1061/(ASCE)0733-9437(1989)115:6(1000)

[20] Amir, Md.S.I.I., Khan, M.M.K., Rasul, M.G., Sharma, R.H. and Akram, F. (2013) Automatic Multi-Objective Calibration of a Rainfall Runoff Model for the Fitzroy Basin, Queensland, Australia. International Journal of Environmental Science and Development, 4, 311-315. https://doi.org/10.7763/IJESD.2013.V4.361

[21] Refsgaard, J.C. and Knudsen, J. (1996) Operational Validation and Intercomparison of Different Types of Hydrological Models. Water Resources Research, 32, 2189-2202. https://doi.org/10.1029/96WR00896

[22] Nash, J.E. and Sutcliffe, J.V. (1970) River Flow Forecasting through Conceptual Models Part I-A Discussion of Principles. Journal of Hydrology, 10, 282-290. https://doi.org/10.1016/0022-1694(70)90255-6

[23] Aneljung, M., Sassner, M. and Gustafsson, L.-G. (2007) Sensitivity Analysis and Development of Calibration Methodology for Near-Surface Hydrogeology Model of Laxemar. 126.

[24] Hafezparast, M., Araghinejad, S., Fatemi, S.E. and Bressers, H. (2013) A Conceptual Rainfall-Runoff Model Using the Auto Calibrated NAM Models in the Sarisoo River. Hydrology: Current Research, 4, 148.

https://www.omicsonline.org/a-conceptual-rainfall-runoff-model-using-the-auto-ca librated-nam-models-in-the-sarisoo-river-2157-7587.1000148.php?aid=11487 https://doi.org/10.4172/2157-7587.1000148

[25] Odiyo, J.O., Phangisa, J.I. and Makungo, R. (2012) Rainfall-Runoff Modelling for Estimating Latonyanda River Flow Contributions to Luvuvhu River Downstream of Albasini Dam. Physics and Chemistry of the Earth, Parts $A / B / C, 50-52,5-13$. https://doi.org/10.1016/j.pce.2012.09.007

[26] Tiwari, H.L., Ankit, B. and Deepak, C. (2016) Simulation of Rainfall Runoff of Shipra River Basin.

[27] Yadav, A., Tiwari, H.L. and Galkate, R.V. (2019) Rainfall-Runoff Modelling Using Mike11 Nam for SHER River Basin Model. International Journal of Recent Technology and Engineering (IJRTE), 8, 9.

[28] Wakigar, S.A. (2017) Evaluation of Conceptual Hydrological Models in Data Scarce Region of the Upper Blue Nile Basin: Case of the Upper Guder Catchment. Hydrology, 5, 49.

https://www.researchgate.net/publication/321640357 Evaluation of Conceptua 1 Hydrological Models in Data Scarce Region of the Upper Blue Nile Basi $\underline{n}$ Case of the Upper Guder Catchment https://doi.org/10.3390/hydrology4040059 